\title{
The Pro-Life Paradox of Pregnancy Termination and Disability Exclusion
}

\author{
Gynecology and Women's Health Care
}

Research Article

Shannyn R. Snyder, MAIS

Department of Global and Community Health, College of Health and Human Services, George Mason University, USA

\author{
*Correspondence author \\ Shannyn R. Snyder, MAIS \\ Department of Global and Community Health \\ College of Health and Human Services \\ George Mason University \\ USA
}

Submitted : 10 Dec 2020 ; Published : 30 Dec 2020

\begin{abstract}
The debate over the use of genetic testing to inform expectant mothers regarding fetal anomalies, with the intention of enabling her to decide whether or not to terminate pregnancy based on testing outcomes, is arguably deemed by many physicians and scientists to be major medical advancement. Proponents of testing believe that this information prevents the potentiality of lifelong suffering for of the unborn child, as well as encourages a healthier population. There are, however, scientists, geneticists, theorists, and disability advocates, who disagree with this theory. Furthermore, pro-life allies appear to take very differing stances on this topic, from opposing any termination of pregnancy, even in cases of severe disability or a likelihood of infant or maternal mortality, while some may believe abortion is acceptable under these unique circumstances, even if they oppose others. It is difficult to understand how the criteria is evaluated, particularly in cases of the former, when support and resources for disabled persons are greatly lacking, which can lead to a more challenging life, and when the stigma of bearing and raising a defective child is widespread. Thus, it is a crucial topic in women's studies to understand when there is a pro-life paradox of disability exclusion is and how it may inform decision-making and advocacy regarding selective termination of pregnancy.
\end{abstract}

\section{Introduction}

The term "paradox" has been used in public health to characterize a phenomenon, variable, or outcome that bears additional research in order to explain. In the context of feminist disability studies, selective termination examines the foundations of fetal genetic testing and how that may impair the value of those living with disability or illness. To this end, feminist disability studies criticize the choice of selective abortion rather than focus on narrowing the disparities in health equity and social justice faced by persons living with, or who may potentially develop a disability, and asks for a deeper analysis as to why support for those populations are greatly lacking.

While this paper also studies the controversial opposing pro-life and pro-choice viewpoints on abortion, its purpose is not to take a political, moral, or religion stance, but to instead highlight the pressures and judgments that women face when making important reproductive decisions. More importantly, it also emphasizes that there is not a singular basis for early termination, and there may indeed be valid moral arguments against its use in certain circumstances. The goal is to provide a deeper understanding of nonbinary derivations of choice, and components of informed decision-making are unilaterally offered here. Therefore this paper, seeks to understand opposing advocacy, with regard to the matter of pregnancy termination due to varied anomalies, with an emphasis on disability, and why proponents may support or deny termination on the basis of their beliefs or, alternatively, if their views circumstantially change. These viewpoints directly impact the reproductive power of women to make both informed and supported decisions during pregnancy. Thus, it is relevant to recognize the bias that may exist for her choices.

\section{Pro-Life vs. Pro-Choice: Understanding Opposition}

When seeking to understand the deeply emotional and often combatant perspectives on abortion, feminism strives to support a woman's reproductive power in any context. Whether someone is pro-life or pro-choice, personally or in partisanship, has little to do with the wider issue of preserving women's reproductive rights, regardless of one's own individual convictions. This would include supporting women who desire pregnancy and motherhood, as well as those who are voluntarily childless, asexual, gender-neutral, or who may wish to terminate pregnancy under all circumstances. It calls attention to a societal stigma associated with women who do not wish be mothers, as it goes against the grain of gender expectations and normative roles, as the value of motherhood is treated with more importance than her own autonomy. Autonomy in this sense is for one's own, and decision-making based on her own circumstances. Pro-life advocacy thus challenges a woman's autonomy and creates a concern that her body must be managed and policed. 
Another paradox here questions why pro-life advocates may unconditionally sanction abortion limits to all unborn children, but may also limit visible and evocative support to certain children, after birth. This may extend support to women during pregnancy, but it may not include resources to help a new mother experiencing post-partum hardship. This paradox also highlights a contextual difference between being pro-life and pro-birth, which denotes advocacy for the rights of a fetus, but diminishing support for children after they are born. This is a highly critical challenge, and one that is a relevant issue United States' social justice, when there are marked disproportionate disadvantages for children in many marginalized populations, including immigrants, blacks, Hispanics, Native Americans, any anyone in a lower socioeconomic group. These children lack

- affordable healthy foods and adequate nutrition

- $\quad$ access to good schools and supplies for an education comparable to that in wealthier districts

- lack of safe housing and neighbourhoods

- healthy environmental qualities in their homes and community

- governmental and community support when one or more parent is a non-English speaker, incarcerated, migratory, or an immigrant

- $\quad$ equitable childcare with qualified caregivers

- affordable and encompassing healthcare.

The discourse of disability also questions the affectation of support for women to terminate pregnancies based on fetal defects, but the choice to bear a disabled child is often met with stigma. Thus, is the stance of pro-life advocacy to support selective termination based on genetic anomaly only, but is against abortion if those circumstances are absent; or is it only preservation of the right to life of an unborn child, but does not address a right for equity through life-long accommodations and resources for that child after birth? For the carte blanche always against camp, this would also be without regard to any social determinants of health.

Whether or not this assumes an able-bodied and cognitively normal child or simply disregards potential defects, the prolife assertion is typically that all children have the right to life. For pro-choice advocates, the hypocrisy of this definitely lies in the lack of support and resources for that child later in life, particularly if they have physical or mental disabilities, and the stigma attached to these disabilities for both the mother and the child.

To understand these opposing viewpoints in the United States, it is important to understand the history of women's reproductive power. Similar historical perspectives also exist for other countries, shedding light on the lack of agency that women globally experience regarding their own reproductive choices, when their bodies are closely and critically regulated by the state.

Prior to the 1960's women's liberation movement in the United States, obtaining an abortion was not only illegal, but also typically unsafe, expensive, and inaccessible. Although it is estimated that as many as one-quarter of all pregnancies were terminated annually, many of these were done at great risk to the mother, including ingesting poisonous chemicals and staging violent accidents. A woman living in a low-income or rural area would also need to travel to a larger city in order to find a licensed provider, whom would be able to safely perform the procedure. However, these safer methods were only for "legitimate" circumstances, such as if the pregnancy would be at great risk to the mother, or if there was an implication of disease or illness that could harm the baby [1].

Prior to the landmark United States Supreme Court case, Roe v. Wade, women also needed the express permission of their spouse or the father of the child, or if they were a minor, the consent of a parent. Many women in undesirable circumstances found that their choice to seek abortion was also governed by religious guidelines and pressures. The Catholic Church, for example, considers abortion to be a moral sin, with the belief that life begins at conception, and that this now human life that must be protected [2]. This is also a timeline that is widely adopted by pro-life advocates, although certain state abortion laws adopt more scientific premises that a pregnancy is viable only at other certain post-conception stages, and therefore, not yet a baby.

In thinking about the timeline for when life begins, the Catholic Church is not the only entity that believes that viability is at the time of fertilization, or when the sperm meets the oocyte or egg, and penetrates it. These stages provide a subjective basis for when this process becomes a child. Even after the zygote is formed, which then experiences the biologic replication processes that create an embryo, this stage is still an approved time frame for an abortion in most states [3]. The longer a woman is along in her pregnancy, however, the access to a legal abortion narrows. As the embryo moves through a series of stages of development, there are differing perspectives on its viability. These stages include three trimesters:

1. the first trimester, when the embryo develops into a fetus

2. the second trimester, when the fetus further develop its major organs and their systems

3. the second trimester, when the fetus is now an infant, which now has an increased potential for survivability if born early, outside of the womb [4].

The details of development during these stages are what make the arguments for and against choice so contentious, as some believe that life begins at conception, others believe it is not until a heartbeat can be detected by fetal ultrasound, which is as early as 3 weeks, or some draw the line for abortion at 8 weeks, when all major body systems have started stages of development. Since Roe v. Wade gave states the ability to decide at what stage abortion is allowable in their state, or alternatively, no longer allowable, laws greatly vary by state. A few states require abortion to be within the first 3-6 weeks of pregnancy, but some allow as late as 30 weeks along, but that is rare. When scientific opinion of fetal viability also differs so greatly, the average state limit is around 23-27 weeks, often asserted that that is when a fetus may be able to feel pain $[5,6]$. 
In a patriarchal society, the liberation of women to have a voice in formerly solely governmental matters, such as with post-suffrage movement voting rights, and agency over their own reproductive rights, such as with birth controls and access to abortion, is considered politically and ideologically problematic. One reason for this is often a matter of maintaining control over the masses and the concern that when you give large groups of people more autonomy, they may become difficult to manage. It's a superstructure fear of lawlessness. There are plenty of parallels here to other historical movements, including Black Lives Matter. Theoretically, this is arguably Marxist, between base and superstructure, as the aim is to maintain separation of the classes and elite control. When the base outnumbers the superstructure, this control is necessary, and it is manifested through laws, cultural norms, and bio politics.

Foucault also describes the atonomopolitics of this structure, with a desire to encourage "docile bodies," or those that are pliable to the rules and guidelines of the state. Bodies that are not docile are nonconformist, difficult, and potentially threatening [7]. We can also conceptualize this in terms of the disabled body, which faces both state and societal fears and aversion, because it is also not docile. It may be rigid, non-normative, nonconforming, or complex, and therefore also a threat to controls.

When Roe v. Wade was enacted in the Supreme Court in 1973, the case set precedence for laws which protect the liberty, or the right, of a woman to seek termination of pregnancy, without unilateral restrictions by the federal government. This law places the burden on states to enact policies that were deemed appropriate for their states, which weigh heavily on the will of the people, who vote for these measures during general elections. Unfortunately, although no state is able to completely disallow a woman to seek an abortion, these laws are typically partisan and with a heavy emphasis on religious preference and liberal or conservative ideology. That is, certain states can make it extremely difficult and very stigmatizing to receive an abortion. There are two states that recommend abortion within the first week of pregnancy, when the majority of women do not yet even know they are pregnant.

Many states imposed structures that limit abortion to the very earliest stages of pregnancy, such as between 4-6 weeks, while others allow abortion into the third trimester, but only for specific medical reasons [8]. Planned Parenthood, a leading organization for women's reproductive care in the United States, particularly in terms of access to obstetrics and gynecology, birth control, and general healthcare especially for low-income, minoritized, and marginalized women, informs women that the earlier they can make a decision regarding abortion, the more likely that one may be able to be performed without potential accessibility or legal issues, but that as the pregnancy enters the $20+$ week range, it is more difficult to find a provider who will perform the procedure if they legally can [9].

This is a crucial point, as prior to the legalization of abortion many women who sought the procedure faced horrific and mutilating circumstances. Giving women clear guidelines on the time frame with which the procedure can be performed, as well as safe and affordable access, saves women's lives. Of course, that is where pro-life opposition argues that a mother's life is not more valuable than that of the unborn child. This argument aside for now, the issue facing women in Poland may be a threatening glimpse towards the future of reproductive rights in the United States, where a conservative Supreme Court may be able to overturn Roe v. Wade. Polish women, facing a unilateral ban on abortions moved in mass protest in October and November 2020, until the ban was tabled. The measure to ban abortions was due to pressures from the Catholic Church and religious right, which have a stronghold in Poland, to curtail the more than 1,000 abortions which occur in Poland each year. The measure would make abortions illegal, except in cases "where the fetus is so deformed that it could not survive after birth," and no allowance for other abnormalities or defects, including intellectual disabilities, such as Down's syndrome [10].

Even though abortions are currently not illegal, Polish women will still face many obstacles trying to obtain a safe, medicalized abortion, which means they will have no choice to continue to seek risky options, including underground procedures [10-12]. Similarly, in the U.S., the overturning of Roe v. Wade and other laws protecting the reproductive rights of women would relegate thousands of women to seeking less safe, illegal, and poorly accessible means for aborting a pregnancy. Depending on state residency, some women already must travel to other states with less restrictive policies, when they live somewhere that requires abortion within the first few weeks.

Again, the issue here is not to take the moral or religious stance on abortion, but rather to consider whether or not the government should be able to regulate and police women's bodies and to decriminalize the right of a woman to govern her own body.

Researching women's opinion in developing countries on the concept of reproductive rights, the idea of having a pro-choice option is a largely inaccessible and extraneous for them. For most women in patriarchal societies, especially where there are extreme differences in socioeconomic structure and class divide, there is no women's choice debate, because reproduction is considered to be one of coercion, with a long, unwavering history. For women living in countries with strict state controls, historical measures of forced sterilization, population control, and bioracism are tools to keep women reproductively disempowered [13]. For countries where there may be an option of choice, women are required to seek her husband's permission prior to an abortion. Many of these countries have the same authorization requirement for birth control pills and elective tubal ligation [14]. Again, here the context is not whether or not it is prudent or normative for these decisions to be made within a marital or similar partnership, but instead whether a woman should have a say over her own reproductive system, regardless of anyone else's views on the matter, including that of her spouse/partner. 
Patriarchal controls also include negating a woman's consent for sex, which is why unwanted pregnancies may occur in the first place, as it also ignores any preferences that a woman may have for contraceptive or disease protection. This puts the control of sex in the hands of man, but the victimization of pregnancy, solely by fault of a woman. There are numerous studies that discuss that in particularly machismo societies, both women and men have access to prophylactics, particularly condoms, but men refuse to use them, alleging that the barriers diminish their pleasure during intercourse [15]. To this end, there has been a marked increase in the prevalence of HIV among monogamous, Hispanic women, for example, because their husbands may engage in unprotected, extramarital, sexual relationships while away on seasonal migratory work, typically with sex workers, who also engage in unprotected sex with multiple men. This creates an environment rife with the potentiality for sexual transmitted infections and disease, including HIV. These men then return home to engage in sex with their wives, who then contract the virus $[16,17]$. There is additional cultural stigma and shame associated with HIV and other diseases for these married, monogamous women, who are often aware that they may pass down infectious disease to their unborn child. Research shows that Hispanic women may also believe that diseases, such as breast cancer, are a result of sin or a bad deed that they are being punished for, and they will often not seek medical attention or interventions, due to shame. Incidentally, this has caused an increasing prevalence of women in these categories to seek faith-based help for disease, such as asking forgiveness from their church priest during confession, which is arguably not the same as seeking advice from a physician [18].

Again, if we are thinking about illness as a disability and the possibility of important health information informing a woman's decision to continue with a pregnancy, this would be another example of when a woman may choose termination. However, in this case, both cultural and religious controls, from machismo to Catholicism, as well as lack of access to interventions, limit any opportunity for choice regardless.

There are some pro-life supporters who take their stand on rejecting abortions except those in cases of disability diagnosed in pregnancy. An editorial in Conception questioned why abortion of a non-defective child is considered to be problematic, but the termination of a defective child is "tragic," provoking sympathy, because it was otherwise a wanted pregnancy [19]. This piece is important because it exemplifies the paradox of being positionally pro-life in some contexts, but allowing for choice in others. It may come down to semiotics here, too, in that pro-life conservatives may believe that selective termination due to genetic defect is actually not a choice but inevitable requirement or responsibility, thus still aligning with their ideologies and principles [20].

Abortion vs. Early Termination: The Semiotics of Meaning In order to understand some of the moral issues regarding reproductive choice, it is important to look at the semiology of the word abortion, and the imagery it conjures, wherein sim- ply the terminology used in these discussions can have very different connotation. In a Barthes approach to understanding meanings and symbolism, it appears that the term and meaning abortion may be associated with the act of aborting a child, as an elective form of birth control [21]. It is assumed in this interpretation, that the mother does not want to be pregnant at all, and is therefore aborting the baby. This implication is thus associated with higher stigma and the assumption that the person may be immoral, self-centered, irresponsible, and probably, single, which carries an entirely different set of societal disapproval. Again, regardless of circumstance or situation, the structural stereotypes that surround women matter, as these may not only inform their decisions to exercise personal liberties, but societal judgment may also have an adverse effect on their mental and physical health, leading to

- feelings of shame over seeking an abortion,

- avoiding telling others about their decision, and

- $\quad$ isolating though the procedure and the aftermath of healing. When abortion evokes feelings of negativity, secrecy, and, in a religious context, $\sin$, it therefore appears to be entirely elective and a choice steeped in emotional, physical, and moral consequence.

Early termination appears to be a more clinical term, denoting a medically-informed and physician-led procedure (versus the illicit, underground act of abortion, even when that is not the case). The circumstances surrounding early termination may also garner the sympathy and support of others, regardless of pro-life or pro-choice convictions, as it could carry the assumption of an otherwise wanted pregnancy, which is unfortunately ending due to necessity and beyond the control of the pregnant mother.

Despite the assumed differences in these terms, the words are actually used interchangeably by medical professionals and reproductive support entities, such as Planned Parenthood, as well as reproductive rights groups. Their emphasis instead is ensuring that a woman fully understands her decision and the options for procedures, which carry the concrete differences, such as surgical or pharmaceutical procedures, as well as to explain the types of abortions which can occur in a pregnancy, such as an induced abortion, such as with selective termination or an unviable pregnancy (which may require a $\mathrm{D} \& \mathrm{C}$, or a dilation and curettage), or a spontaneous abortion, also known as a miscarriage $[4,22]$.

Unfortunately, the issue with semiotics and meanings is also that women must police their own conversations about reproductive rights, due controversial language, negative connotation associated with desiring to have autonomous choice, and the necessity of exercising reproductive options in secrecy because of stigma.

\section{Choice vs. Necessity: A Perspective on Decision-Making}

The grounds for early termination of pregnancy, as an outcome of genetic testing, from the perspective of both disability and feminism, is most contentious when considering this opinion of choice versus necessity, including scrutinizing the struc- 
ture that sets this standard of discrepancy, and why a woman's choice would matter to others, even in the context of their political, religious, or personal beliefs. That is, should not the "her choice doesn't need to be my choice, but I'll still let her have her choice" thinking just simply be adopted? This conceptualization is significant, since herstory is her own, and it is one of the most relevant arguments for the preservation of women's reproductive rights [23]. This decision and the procedure are happening to her, and the determination of outcome should be hers, and not governmentally regulated or familially controlled by others. To wit, for the woman considering abortion, the choice may not seem elective at all, regardless of reason, and her vantage point is singular. She will be the only one to fully understand the very personal and deeply-felt significance of this resolution. That is, only she is inside of her own psyche.

Rising up against the control and policing of women's bodies was one of the key principals of the second wave feminist movement in the United States. Women were asking for equal opportunity and pay in the workplace, as well as choice in of family dynamics and sexual orientation, acceptability of career over motherhood, and a recognition of sexual freedom, which included sex before marriage, untraditional partnership structures, a potential of multiple partners, and non-stigmatic use of birth controls and prophylactics. Women desired autonomy at work and at home, which included deciding on their own timeline for having children. Most women simply wanted the government to stay out of their reproductive choices, from birth control to pregnancy.

Although it has not been the only law to take on abortion in the United States, Roe v. Wade is the most notable, as it set the precedence for a woman's right to an abortion and the preservation of her privacy in that regard. As aforementioned, the states were still given the latitude to set varied restrictions, but for many women, the groundbreaking acknowledgment of choice was a start, and there have been other legal cases since that time, both narrowing and widening the margins of abortion rights, particularly in the case of a threat to the mother's well-being.

Conceptualizing well-being gives us a critical look at the marginalization of women in circumstances in which abortion may be the best choice for her physical and mental health. This will is largely ignored by pro-life supporters, as some fail to comprehend the inequities faced by women in certain socioeconomic levels, and those with compounding social determinants of health, since their views come from the vantage point of privilege and wealth.

One example concerns women experiencing substance abuse, which carries the potentiality of criminalization via fetal harms laws. Women who engage in risky behavior, such as drug abuse, can be charged with child endangerment or fetal homicide. While any woman should consider the effect that any adverse health behavior may have on a fetus, these women may already suffer systematic discrimination and oppression, which leads to poor health choices [24]. There is also an asser- tion that women in these situations may choose to abort their baby to avoid the more serious charges associated with these harms, adding another lens to this topic. This means that, when properly advised, these women may be able to avoid the intentional infliction of harm on their child.

Women who circumvent these consequences and choose to have their baby anyway, may soon face with other problems, such as giving birth to a baby with neonatal abstinence syndrome (NAS), requiring complex medical care and the potential of criminal charges. Although certain state and county jurisdictions with epidemic opioid crises recognize the prevalence of addicted women, who may then become pregnant, have created affordable and accessible opioid abuse mitigation programs, in which a woman may receive medical interventions for her addicted newborn baby, if she commits to rehabilitation and care for her own addiction. If she does not comply with the program, however, the new mother may face jail time for drug misdemeanors, criminal charges for child harms, and may need to relinquish the parental rights to her child [25].

In the absence of these governmental or NGO programs, treatment for NAS is expensive and a long-term commitment, which is a resource that a mother whom is impoverished, addicted, currently or formerly incarcerated, and most importantly, transient, may not have adequate access to, adding to an argument that mothers in certain social demographics, in general, have a diminishing lack of resources during and after pregnancy for their needs and for the potential needs of their disabled or ill child, especially those in vulnerable and marginalized populations.

Another compounding issue is the perceived burden of crack babies on the system, a message that was a part of the fear-mongering in the United States' war on drugs, which was articulated to "prevent poor black women from getting pregnant" [24]. In addition to the implicit and explicit racism that black women, and other women of color, particularly those with multiple children, regularly experience in structural institutions, such as obstetrics care and hospital labor and delivery, these discrepancies lead to their higher maternal and infant mortality, compared to white women [26,27]. Women of color and their children are regularly categorized as costly and therefore disposable, particularly if there are other compounding variables of minoritized health.

There has also been a long-standing history of the illicit practice of nonconsensual tubal ligation and forced sterilization of incarcerated women, as well as those in other marginalized populations, such as Hispanic women and, allegedly, undocumented immigrants currently housed at border prisons. Their children, who are often separated from them at the border, are vulnerable and disadvantaged due to socioeconomic and citizenship inequities. Parallel studies in other countries with similar situations prove that these children will suffer, possibly permanently, from a wide range of physical and mental health issues. It is with great hypocrisy that these children are also treated as an expendable population, often by those whose po- 
litical and policy ideology is asserted as pro-life.

As a second example, the oppression of Native American persons shares a dark similarity to the discrimination against black bodies. The adverse treatment of Native American Women, including sexual violence, lack of power, victimization, and potential criminalization has a long-standing history in the United States, steeped in the violent circumstances of early colonialization. There is a rampant lack of support and women's resources for Native women on tribal lands, and many Native women have been victims of sexual assault and rape by family members and others living on tribal lands, and by men outside of native lands who act criminally with impunity, due to the structure and limitations of federal and tribal laws [28].

Although normalized for men as perpetrators, rape is stigmatic and traumatic for women. Women and girls who become pregnant with the child of their rapist can face further abuse, stigma, and ostracization or shunning by their families, but abortion is a complex problem for Native American women, from spiritual morality to lack of access. Native spirituality treats all life as sacred, yet pregnancy due to sexual assault is typically unwanted and stigmatized, thus the complex contradiction. Native women also have very few social resources for help in these circumstances. Women who press charges against their rapist are often ostracized, shunned, and outcast, and their children may be taken away in a divorce, so most will stay with or continue to live among their abusers.

Native women who are raped often have secondary trauma, such as post-traumatic stress disorder or substance abuse addiction. Research finds that these stressors continue to manifest into additional health issues, including chronic illness and disease, such as high blood pressure and diabetes, often due to the mechanisms used for coping, such as drugs, alcohol, and unhealthy eating [28].

Also, as aforementioned in terms of fetal harms laws, Native women are also subject to the same legal ramifications, if they endanger a child or cause fetal death due to addiction. There have also been accounts of Native girls and women hiding their pregnancy and bearing a child in secret, and then, either purposefully, or due to unforeseen circumstances, the child dies or is killed, and then they bury the stillborn or otherwise deceased child in an unmarked grave. These deaths and burials may go unnoticed forever, but for some, they are discovered, the mother found, and the crime punished as murder, even in the case of a stillborn or extremely ill child. This widens the discussion over the desperation that some women face when pregnant, especially due to lack of resources and stigma, and whether both the mother and the baby are victims [24,28].

Genetic Testing vs. Eugenics: Medical Advancement or Biopolitics?

To further understand reproductive choice, it is necessary to understand biopolitics, eugenics, and the premises for genetic tests, with the thinking that genetic testing may actually be using science irresponsibly as a "means to reinforce racial prej- udices," noting the historical precedence for genetic testing, which includes the use of eugenics to exclude certain types of people from society [29]. Genetic testing may also theoretically support the "...ideology that one is better off dead than living with disability [30].

Historically, eugenics is often associated with its use under Nazism in an extermination program known as the Holocaust. Without any scientific proof to corroborate the assertion of racial superiority, Nazis claimed that Jewish persons represented genetic inferiority that threatened the superiority of the human race. Jewish people were not the only targets, however, as other undesirable populations in countries oppressed by this regime, namely homosexuals, people of certain religions, such as Jehovah Witnesses, people from other ethnic backgrounds, and those with mental and physical disabilities, were also executed as a part of this state-sanctioned genocide during World War I [29].

This connection to alleged genetic superiority and inferiority also explores the predicate that the creators of this testing assert, which that it has the benevolent intention of reducing human suffering, by preventing people with unlivable disabilities from being a burden onto themselves, their family, and society, but [critics argue] that it sets an unreasonable, unethical, and inhumane "criteria of human worth" [29].

However, perhaps we must analyze the semiology of words here, too, as "[Disability studies may] draw an important distinction between prevention and elimination, [contrary to a geneticist's point of view]. Preventing illness, suffering, and injury is a humane social objective. Eliminating the range of unacceptable and devalued body forms and functions [considered by the dominant structure to be disabling] is, on the other hand, a eugenic undertaking" [31].

Another viewpoint is the belief that the same professional and societal support of a woman to terminate a pregnancy should also be present if a woman decides to continue with the birth of a disabled child, such as through healthcare and medical and social resources for assistance and interventions [29]. This would encompass family support for a wide range of disability variants, from physical to cognitive disabilities, such as spine bifida and Down Syndrome, to genetic markers for diseases which may or may not ever lead to disabling manifestations, or, if so, much later in life.

This also gives pause to think about what family markers for disease say about the value of family members who have lived with or are currently living with the disease [29]. Disability theory breaks down the conceptualization of a body using the "ability/disability system," and it categorizes this body on the basis of "[appearance, medicalization, and normalcy"] [31]. This system also factors in the productive value of a body, such as in the ability or inability to perform tasks or a job, or the functionality of that body for normative behaviours, such as bearing children, or the aesthetic value that one may have in a societal system, based on cultural norms and expectations, 
such as appearing attractive and approachable to others, instead of disfigured and feared [31,32].

Additional feminine and disability theorists suggest that a more critical lens is needed to understand genetic testing and the intention of its usage. These echo the problematic lack of resources available to inform a woman's coherent choice to keep or terminate a pregnancy, after the result of a genetic marker for disability has been received. There is an assertion that this test result is then accompanied by the pressure to terminate a pregnancy, based on certain medical assessments or professional opinions regarding the social or economic value (or devalue) of a disabled person. These factors negate the idea that a woman has any choice at all [33].

The discriminatory way that people living with disabilities are treated in society may also make this prenatal testing oppressive, because only the negative aspects of disability are acknowledged, when there have been medical treatments and aids which support people with disabilities, as well as those who are successfully living with disability Yet, this testing is becoming more wide-spread [33]. There may be psychological pressures which also add pressure to terminate a pregnancy, weighted heavily on societal stigma and internalized fears about the gaze of the disabled body. That the disabled body makes ableist society uncomfortable is a disheartening and discriminatory reason to recommend the invisibility of disability via eugenics. Even if the recommendation of termination of pregnancy has a valid health focus, based on the severity of disability or disease, "it is clear that some medical professionals [are using fetal testing and abortion] with the intention of eliminating categories of disabled people, [such as those with Down's syndrome and other disabilities]" [29].

The devaluation and bioracism that plague many marginalized women bears additional mention here. For example, Native women experienced mass sterilizations as part of the federal Family Planning Services and Population Research Act of 1970, which was viewed by some as genocide. The premise behind the sterilizations was to limit the population by quelling the higher than average birthrate among Native women, and to weaken the higher rate of illness and disease prevalent on Native lands.

There have been other forced sterilization programs and incidents in the United States and abroad, many of which targeted other populations of women of color, but they are not the only victims. Incarcerated women, those whom are institutionalized, and disabled women have also been subjected to these practices. Some of these programs are, similar to the Native American sterilizations, for population control, but others are specifically directed at preventing a particular population from continuing to reproduce, particularly to "ensure the able-bodiedness" of society [34].

This highlights a long history of dispute between a woman's reproductive power and those who have the power over her reproduction, and we should question the motives. Foucault, for example, provides a theoretical look at who has the pow- er to choose who lives and dies, specifically addressing those practices founded in imperialism, such as the "ancient right to take life or let live" as now "replaced by a power to foster life or disallow it" [35]. This "procedure of power" may also prove the existence of eugenics as a means of organizing populations by preference to society.

There may also be able cause to consider genetic testing as a positive approach to health advocacy, not by disavowing disability, but through an intention to support it. Not all women choose pregnancy termination based on the results of these tests, using the results instead as a tool to emotionally and physically prepare for a child whom may be potentially born with a defect. These women may not be ideologically pro-life, but instead feel equipped for the challenges of parenting a disabled child. This is another aspect of reproductive power that bears attention, as these women are essentially making the choice to face the probable challenges and stigma that accompanies disability or disease. It could be an "authentic joy of raising a child with Down's syndrome," having personal, lived experience commensurate with the potential disability, or, by contrast, they could be romanticizing the situation $[29,33]$. However, this choice could also be because a woman is ideologically pro-choice, so regardless of the test result, she is always already proceeding with the pregnancy.

The decision may not always be so clear cut either, as parents may be "(...encouraged) to consider what level of disease/disability is acceptable and manageable for them and their families" [36]. Disability advocates may also find this basis for decision-making discriminatory, however, since a family may not always be responsible for this management, which in itself is considered to be a derogatory association to disability, with various feminist disability theorists explaining why the "management of disabled bodies" is oppressive in both concept and terminology [37].

The results received from genetic testing, whether it is prenatal, antenatal, or testing one's own DNA through a service or geneticist as an adult, could be regarded as a powerful information highway and a potential crystal ball for a person's physical or mental health future. Genes which signal anomalies for breast cancer, macular degeneration, and even Alzheimer's disease, can be crucial tools to enable a person to be proactive and prepared for their health outcomes. Genetic testing can also provide meaningful validation that one's symptoms or chronic illness, disease, or disability is due to a genetic anomaly and not an outcome that could have been prevented.

In one case in Brazil, a set of brothers suffered from symptoms of ataxia for years, which included slurred speech, falling down, and other manifestations which mimic the appearance of intoxication. Family members treated the problems as if they were imaginary or exaggerated, or that the brothers were actually drunk, until one sibling sought out genetic testing to confirm a diagnosis of something they knew to be a familial disease. The brothers found this genetic information to be both relief and affirmation, as well as way to move forward with ap- 
propriate palliative care and interventions, even though there is no overall cure for ataxia. Often carried in families, the brothers asserted that this information was also a way to prepare for future family members who may present with the same symptoms, but this did not include terminating future pregnancies to avoid the possibility of ataxia and its associated disabilities [38].

Incidentally, in another example in Brazil, 50 children were born into a family with a history of ataxia, some with varying symptoms of the disease, while others had no discernable presentation. This opens the discussion about able-passing and severity of disease, as genetic testing can only show markers for disease, not if, how, and to what degree of severity that it may manifest. Thus, women may not always automatically choose termination of pregnancy, based on what might happen in the future, in terms of the disease progression. Women who do choose termination of pregnancy based on an always terminate approach, if prenatal genetic testing shows defects, must also consider that despite a positive result, their child might never have had any disease symptoms or appearances of disability, might always have been able to be able-passing, and may have had a productive and livable life, whatever those descriptions may entail [38]. Perhaps that is an the emotional consequence of abortion, making it one of the more viable arguments by pro-life supporters. However, when physicians recommend termination based on worst-case scenario outcomes for diseases and defects, the culpability of conscience may be replaced by believing you have done the right thing by potentially sparing the child of a lifetime of suffering, which was arguably the scientific intention of these tests in a prenatal context (versus the eugenic one).

A critique of maternal interests must also continue to analyze the importance of genetic testing as an obstetric practice. In an essay which includes the reflections and recommendations of 25 disability rights advocates, social theorists, academic and medical doctors, and researchers, there is exposition regarding the use of genome technology to determine undesirable defects during pregnancy, particularly its implications for the perpetual disavowal of disabled persons as valued members of society [39].

Although tests have advanced to already include "gene mutations associated with some 400 conditions," this number continues to grow, as does the perception that this testing is an integral part of "good prenatal care," because testing helps to ensure a healthy baby. The idea that only able-bodied children make up this category of health is of great concern to the disability community, as it seeks to negate the livability of even one "single trait they bear." Hundreds of these markers may show a positive result for one single, possible defect, which may not materialize in any level of noticeable severity [39]. This is a cause for concern for disability advocates who believe strongly that these test advancements represent a proactive intent to eliminate certain attributes from society and a clear message that defective, diseased, and disabled bodies are unwanted and even appalling.
Critics of a prenatal disability-prevention tactics also question whether other prenatal measures to prevent disability are also ableist, such as taking prenatal vitamins to prevent birth defects [39].

People living with disabilities have vocalized their opinions about selective termination, and whether or not they wish they had not been born, due to the challenges of navigating livability, access, pain management, or other circumstances that they believe outweigh the positive aspects of their lives, understanding that their defect traits are testable, and if that has had any impact on how they feel about the potentiality that their lives would have been aborted. These testimonies are not measureable as statistics to validate whether or not testing and abortion are thus appropriate or disabled-approved, as these experiences greatly differ, just as do types and severity of disabilities. They serve instead to reinforce the considerations that there is not one-size fits all guidance to using these tests, and no one is able to say for certain that utilizing them will lead to making the right decision, or that they could be making the wrong one. Disability advocates also reiterate that advancements in prosthetics and accommodations signify that normate life can be fairly navigable as a disabled person. People living with disability may or may not decide to use aids, as some people may find these open the possibility for immersion, such as by learning to use Braille, while others may find aids to be a cumbersome or an oppressive expectation [41]. Some may rank their disability or pain in terms of severity, understanding that while their symptoms may be minor, that others may not be sharing the same livability. On the contrary, some persons living with disability may share that their lives have been traumatic and unbearable, wishing they had not been born, drawing attention to another controversial subject: euthanasia or the right to die.

Some people living with disability have also mentioned that while life has either proven manageable or challenging for themselves, that they would not choose to have a child with the same disabilities [29]. This underscores another paradox: disabled persons who would terminate a pregnancy based on fetal anomaly showing disability.

Defect Anomalies vs. Designer Babies: Is it a Matter of Health or Preference?

A law review article discussing Roe v. Wade and Doe v. Bolton, clearly demonstrates the progression of women's rights, but it is also a reminder that laws may be repealed and court cases overturned, so it is important for advocates of feminism to pay attention to state laws, insurance parameters, and even employment benefits, to watch for cracks in the system. Doe v. Bolton is a significant case for women who live in states that have severely limited access to abortion. In one important part of Roe v. Wade, "the Court recognized a number of potential psychological and physical 'detriments' confronting pregnant women who are denied the choice of abortion," but it did not address specific reasoning behind abortion, like it does in Doe v. Bolton. In Doe v. Bolton, "maternal interests or detriments, including selective abortion due to genetics or 
'advance knowledge of certain characteristics of the fetus,", is also supported. Therefore, a woman who lives in a restrictive state can still access an abortion, but only if she meets certain criteria [42].

This particular case and others have helped to set the foundation for more flexibility regarding abortion, but it could also lead to the exploitation of the practice. To this end, there have been small victories in productive rights and maternal interests, but there have also been constraints. While stricture may be necessary to prevent overuse and abuse (whatever that would construe in these events), just as in the example of Poland, women need to watch for the incremental adoption of bans, which can be deliberately additive over time.

These laws often debate whether a woman's decision to terminate a pregnancy due to preference or circumstance should be treated in the same frame as selective termination due to adverse genetic anomalies. These reasons may include not wanting a pregnancy at this time, not wanting children at all, or if she does not want any more children [39]. However, all reasons for wanting to terminate a pregnancy may carry stigma, regardless.

So, how in the context of supporting a woman's right to reproductive choice do we then address under which circumstances termination is allowed, and when it is not? Is abortion only to be used in the case of a defect? If so, disability advocates argue that defects are not necessarily unlivable. Even if it is legal, is it ethical for a woman desire a male child, instead of a female, and thus exercising her right to an abortion, based on the sex of the child? If so, gender selective abortions may "reinforce discriminatory attitudes towards women," when used to ensure a male child. Masculinity and feminist advocates say that this practice continues to reinforce systems of gender instead of working towards equity.

One opinion points particularly to the precedence that fetal anomaly or fetal impairment abortion set for the more controversial gender selective abortion. That is, if pregnant women can exercise the choice to abort a fetus, due to a disability or other defect detected during genetic testing, that this should include any undesirable "genetic component," including gender [40]. Some feminist theorists assert that gender preference is Darwinistic, but women whom are only able to have one child, either due to financial, career, health, or other constraints, or via limitations of state, may desire a male child because of the idea that they will be physically and symbolically strong, able to support himself and his family, carry on the family name, and may have greater survivability than a female. Women are considered in various cultures to have a weaker build and complex and inconvenient physiology, such as with menstruation, and their skill set is stereotypically considered only to be commensurate with domestic work and not the external labor force.

In developing countries, bearing a biologically female child often also carries stigma, due to these beliefs, as well as the gender roles placed upon them in society [29]. This certainly points to the larger task of dismantling the structures of oppression which dictate that third-world women are sexually-constrained, uneducated, powerless, and confined [13].

This is where the borders of selective termination of pregnancy may begin to appear ethically gray. For those with the always already view against abortion, who even view termination immoral in cases of rape, incest, severe deformities, or health risk to the mother, gender selection is a non-argument, and they would not support its use. For those who believe in choice, they may also feel differently about genetic selective abortion, since disease and disability are defects, but gender is not. Or, is it? This delves into gender theory in a very complex way, since this is about both biological constructs of gender and the social constructs that a person may live with, and whether through breaking barriers of stereotype, or changing or altering gender, that these are actually outcomes that can be altered or potentially overcome? Problems absolutely arise when trying to assess the ramifications of "undoing gender" (and now, overcoming gender), as this is a complicated web of legality, religion, culture, anthropology, physiology, medicine, and mental health $[31,43]$. It also reinforces that there is always something about women, or disability, that must be fixed or cured.

This argument is interesting and relevant, if abortion is ethical, acceptable, and especially legal for some traits, but not others. The precedence for a more liberal pro-choice stance is also what pro-life proponents fear, as permissive policies might lead to the ability of women to have access to abortions for "all kinds of reasons" beyond genetic testing, disability, gender, or disease, but also due to rape or incest (which may still be considered to be an acceptable reason), or at the extreme, a personal form of birth control.

Still, advocates for selective termination based on fetal impairment believe that the legal triumphs in women's reproductive rights have also set the precedence for sex/gender selective abortion, "based on other traits that women may [also] decide are undesirable, [such as] susceptibility to [certain female-prevalent] disease, level of intelligence, physical appearance, sexual orientation, religious belief, and criminality," should the mother believe that "any [of these] traits [are] attributable to some degree to a genetic, [engendered] component" [40].

Again, the emphasis here is not that a woman shouldn't choose abortion because a child will be a girl, but that this decision is only for the woman experiencing that pregnancy to decide which traits may lead to unlivable or oppressive circumstances for that child in the future. Mohanty and other feminist theorists would likely agree that a popular desire not to bear female children will not solve the global engendered issues of moving towards social justice for women, but it can empower women to be able to make all choices regarding her reproduction, especially if that power helps her move beyond systems of oppression that require her to reproduce.

Disability vs. Defect: Defining a Livable Life

Continuing in this theme, situational pro-life advocates may 
argue that living with a disability is not the same as living in a particular gender. Considering gender inequality and violence against women around the globe, there could be valid rebuttal to that approach. To this end, in addition to theory and science, women's rights and politics, biopolitics and intersectionality, discrimination considerations must all be a part of a theoretical analysis of abortion, even if they are not fair or just. Thus, what are the parameters that define a livable life, in the mind of an expectant mother?

What is it about disability, in particular, that makes it so undesirable? Feminist disability theorists offer that people are conditioned in "discriminatory societal, cultural, and environmental structures," where we learn what is acceptable and preferential in terms of "norms and self image," asserting that if not due to eugenics, the dissuasion of visualized disability in society is simply because people do not want to look at it? One idea is that the looking at or the gaze of the disabled body makes us fear our own mortality and perpetuates the fear that we may become disabled [44]. When disabled bodies live within shared spaces, people are perhaps forced to look at what they both fear and disdain most, a disabled body existing and, as in the Allison Lapper Pregnant sculpture, the disabled body reproducing $[34,44]$.

When prenatal testing could have originally been designed out of preference for the able-bodied in society, this testing sends a devaluing and "disparaging message...that disabled people's lives are not worth living" [45]. This is especially poignant when respected medical practitioners and science professionals are at the foundation of such message, reinforcing stereotypes and medicalized stigma "that constructs disability as irredeemably tragic and/or unfathomably burdensome" [46]. Not only does this message put pressure on those living with disability to prove their value within their family and society, but also that they must perform, in some way, equal to the production and contributions made by those who are able-bodied, as well as to endeavor to be independent, even when some or all of these outcomes may not be possible.

Some people living with disability have experienced this $e x$ pectation of contribution. In one example, productivity was not only intended to disprove that disability is a lack of able-bodiedness, but also to defend the assumptions of "weakness and defect" based on her gender. "To her, 'a real defective' was one who could not work or be productive" [30]. This also exemplifies the confrontation that people with complex intersectionality face, when they have systematic structures of oppression, such as race, disability, gender, and lower socioeconomic status.

The perpetual discrimination against disability and disease exists through overt tactics, such as with the inappropriate use of violence and weapons by police against people with mental illness, to micro aggressive exclusions, such as lack of ramps, captioning, or other accessibility. "Lack of accommodation [and oppression] is what's most disabling about disability" [29]. Societies have also been able to create their own rules of engagement with impunity until laws, such as the American Disabilities Act, challenged those structures by acknowledging that disabled bodies exist and should be assimilated into mainstream institutions through a system of accommodations. The World Health Organization shared with its partner countries that "disability is not a tragedy," except for when those persons are excluded from society, highlighting an important perspective that is likely shared by many disabled persons [47]. This proaction to be included, with accommodations, versus treated with disability-blindness or exclusion, may thus be the way to social and health equity, versus terminating a disabled body.

Biopolitical and institutional practices of discrimination and a disavowal of marginalized populations, from physical and mental disability to the intersectional variables that make living with these conditions more difficult, such as poverty, are also drivers for termination decisions, especially if women may otherwise choose not to, if resources and support were available. This questions whether pro-life proponents always already choose not to terminate pregnancy, regardless of reason, solely based on ideology.

An important perspective here is that social determinants of health are typically more of a compounding factor in a livable life, and "poverty [and] malnutrition...place a fetus more at risk [and at a disadvantage] than [many of the diseases and disabilities detected through prenatal tests...]" [29]. So, are disability and defects to be avoided only because they are the most palpable? If only the healthiest and wealthiest women were encouraged to produce similarly healthy and advantaged babies, certainly global demography would look entirely different, as would the prevalence of certain diseases and other adverse health conditions. However, having optional health does not necessarily guarantee that other social determinants will not perpetuate. Wealth may equals health in many cases, but not the other way around.

However, determining one's own fitness for reproduction, in terms of health, would also be highly subjective, especially if a person experiences "eugenic pride" in his lineage, despite the existence of defects and disease [30]. In this case, there would need to be some type of imperial structural standard to dictate in which cases reproduction would be discouraged in order to avoid perpetual cycles of poverty and diseases of the poor, and when they would be allowed, yet that would appear to be the very definition of bioracism [48].

However, in the 1920s, these practices were considered in the United States in the form of "eugenic policies," which were to encourage "fit" and healthy immigrants to have multiple children, as a means to grow the national workforce, and to inhibit the reproduction of criminals, the impoverished, and the sick [49]. Although these policies never came to pass, these tenants of what made good society still perpetuated in other ways, through systems of oppression and racialized applications, such as with the Tuskegee syphilis studies.

Does health and fitness mean both visible and invisible quali- 
ties, and does the decision for pregnancy termination change if the child may be able-passing or if adequate support resources are widely available to bolster good health? Which social determinants weigh into those decisions? If healthcare, social, and financial support, future education and employment opportunity, accessibility, and accommodations, were optimal, would the decision to have a child who presents with a disability be okay? What about the notion of "hope for the cure," such as with surgery, cutting edge pharmaceuticals, or prosthetics and treatments that may deem a disability manageable or invisible? Disability advocates also consider this to be problematic, as it may then appear that we are always trying to fix, hide, or blend disability so as to be normate. It's also a perhaps if we did not address it before birth, we can fix it later thinking [29, 33, 37].

This also brings attention to the array of variants that make up disability and livability. There is also the possibility that "disability is often in the eye of the beholder" [44]. Thus, is a decision more informed upon a physician's warning about the livability of a disease or disability, or is it more informed by a woman's perception of the severity, complexity, visualization, or some other aspect of consideration regarding the defect, and her ability to handle it? Therefore, what is the standard that gauges whether or not there disabilities which are more disabling and less livable than others? [29, 33]

Still, another variation of this disability abortion debate is whether or not there may be a difference between physical disability and cognitive disability, and whether or not the critique of selective termination on the basis of fetal defect is more understandable for intellectual disabilities. If we are comparing the potentiality for a physically disabled person to live a normal life, in terms of

- accessibility,

- accommodations,

- $\quad$ ability to be educated and develop cognitively,

- $\quad$ ability to then learn and practice a skill set that may be employable, and

- $\quad$ whom may be able to use a varied set of aids to mimic able-bodiedness, this may not equitable, or even have the possibility of ever being equitable, for a person who is intellectually disabled.

Therefore, the question arises whether or not it may be unethical for parents to use selective termination based on physical disability, but that may be ethical and even understandable, to enable this choice for cognitive defects [50].

Once again, the question may remain steadfast regarding which abnormalities and aberration are manageable for a family and which are not, but also taking into consideration that those reasons are completely subjective and not interchangeable between families. We may also scrutinize the choice to move forward with bearing a child with known severe intellectual disabilities during pregnancy, and assert that it is only through some type of psychosis that a mother may desire to be wholly depended upon, potentially for the child's entire lifespan, as a means to feel validated herself. This may be an unfair assertion, but the reasoning behind wishing to continue with pregnancy may be called into question, whether or not the mother has strong convictions regarding pro-life or pro-choice.

It is important to consider that many of these prenatal tests are also not without inherent risks to the fetus [29]. Although there are some tests which can be performed by collecting blood, some require tissue to be extracted from the fetus or fluid collected from the amniotic sac. Women are informed of procedural risks, but the disparities between a particular woman's health literacy level and giving informed consent is also a crucial problem in women's health. After consent, if a woman truly understands the risks, including the potential for spontaneous abortion, or miscarriage, as a result of a procedure such as the amniocentesis, it is because the risk she assumes in order to learn if her fetus is affected by defects, is more relevant to her than the overall viability of the pregnancy. This may not be an overt assertion, but it is an assumption that, regardless of the test outcomes, the pregnancy may end up in termination anyway. This level of choice is also a significant example of a woman's reproductive power and autonomy, but it may also be a part of the paradoxical question of whether or not women with pro-life ideology consent to those risks, and if so, can the potential for miscarriage be still construed as pro-life.

If every possibility of trait testing existed, are there other variants of undesirable qualities that would be taken advantage of in pregnancy selection? Critics say that certain physical features, such as skin color, including shades of color, and eye color may be deemed a reason for early termination, if such testing existed. Certainly, the concept of "designer babies" comes to mind, which is the practice of manipulating the embryo to carry certain traits. In one case, a parents' decision to use the science of embryology in order to choose the sex of their baby was met with controversy, as this scientific practice of design was originally only meant as a tool for disease prevention, and all other uses were considered to be unethical [51].

Understanding the disproportionate inequities facing people living in poverty, or the discrimination against LGBTQ persons, if prenatal testing existed for aptitude or sexual preference, how would that be perceived? In one study regarding the relationship between LGBTQ populations and homelessness, there may be an intersection with disability, including mental illness, disease and illness (such as HIV and AIDs), and the disavowal of these populations by family members and society [7]. There may also be a relationship of livability and disease or disability that is directly commensurate with one's wealth and access, where the stigma of living with such a defect may be lessened, based on the affordability of accommodations and care, and the ability to reside where support exists.

By the same token, the intersection of race, socioeconomic level, geography, and disability may look very different for a poor, uneducated, unemployed, disabled woman in the rural South, as an example. This inequity, as the visible is made invisible through lack of power and support, makes these populations virtual social enigmas, until they die, are silenced or forced 
to hide. Thus, we can argue that lives worth living and lives worth saving are indeed ranked socioeconomically in society, and these rankings may include attributes that women may wish to test for, in order to save a child or themselves from needless physical and emotional suffering. How then can we gauge what level of suffering is adequate to a reason for seeking abortion? [16, 52].

These contexts are not limited to the United States, however. Life for those living with physical and mental illness in Brazil, for example, is described as "life in a zone of social abandonment" [38]. This space is described as one of exclusion occupied by many people living with disabilities, regardless of geography, but it particularly describes the inequities, stigma, and lack of resources associated with disability that is especially prevalent in developing countries, especially due to lack of funding and infrastructure. Many people living with disabilities in countries like Brazil are institutionalized, often regardless of severity of their deformity or illness, and a genetic predisposition to a disability or ailment is feared and often shamed. Therefore, the opportunity to seek genetic testing would be optimal here, to avoid a statistically and tangibly proven life of abandonment, isolation, and suffering [38]. Yet, the cost, access, and privilege of such testing evade these spaces. The irony of this for the United States, however, is that as advanced as disability advocacy has reached in terms of acknowledgement, acceptance, treatment, and accommodation, people experiencing disabilities are still not a part of the mainstream here either, existing in an exclusionary zone.

Feminism vs. the Nuclear Family: on the Preservation of all Reproductive Power

In continuing to think about the differences between pro-life and pro-choice advocates, the opinion exists that regardless of where you sit in terms of the debate, women should always support the desires and needs of women, even if they starkly contrast their own. This is meant to be a marked sense of solidarity that emphasizes that the difference between our earned and won liberties in the United States, compared to those lacking for women abroad, must be protected. To this end, women should acknowledge that any repeal of law or further governmental restriction of any of these liberties, could cause a ripple effect targeting women's bodies that would set us back to a time prior to second wave feminism. Should it be argued that if you are pro-life, is this also anti-woman, or is a woman's right to stand in opposition in a women's issue, also an integral part of her empowerment?

The message from pro-choice advocates to those of pro-life shares that "if you don't agree with abortion, then don't have one, but don't infringe upon the rights of others to that access." Pro-life advocates may argue that their convictions on the topic have less to do with the rights of the mother, but "speak for that whom cannot speak," which is the unborn fetus. Pro-choice advocates may counter that one cannot be pro-life when that support contradictorily disappears after birth, or if it only selective provides resources to certain segments of the population, such as donating to a children's cancer treatment center, or when you consider the number of children abandoned, in foster care, and available for adoption (especially disabled children). Debates regarding this difference focus on whether the pro-life stand should instead be called pro-birth, and if it is potentially not about the mother or the child at all, but rather about maintaining systemic control over women's bodies.

A woman's reproductive ability is arguably considered to be one of her greatest powers. In the context of feminist theory, perhaps that is what men fear, as it is the one attribute for which they cannot compete. In addition, her reproductive powder, whether one agrees or not, is solely what makes her life considered a life of value in many societies. Therefore, exercising the right not to have children, as in voluntarily childlessness, or not to have this child, as with having an abortion this time, the issue may actually be that women are a valuable commodity that threatens structured, economic base. Her reproductive power is directly related to her ability to contribute to the economy, either through her own labor or that of her children. In the same frame, both the childlessness and the disabled may cease to support the economy, and are therefore surplus lives $[13,53]$.

Recently, in Hungary, women were called to action to have more children, and the government offered special incentives to do so, such as tax breaks, with the primary reason being to build a future labor force that would support the needs of the economy [54]. Hungary has a large immigrant population, and many young Hungarians moved throughout Europe after the end of the Cold War in the early 1990s, leaving behind a significant elderly population (surplus) compared with women in their child-bearing years. Therefore, the birth rates in Hungary have fallen, which has economic ramifications for the future of a workforce and the national economy. Critics of the policy say that this is meant to only include native Hungarian citizens in higher income brackets and excludes other categories of citizenship and socioeconomics [55]. This may also implicitly emphasize healthy women and the assumption of healthy offspring, although the policy does not specify. Therefore, in the context of lives worth living, perhaps this definition is narrower than we realize, to only include those who can bear healthy children, those who are productive, those who are able-bodied, and those who are docile.

The issue with body autonomy extends beyond reproductive rights, as there seems to be a problematic lack of agency that disabled women have over their own bodies. They may legally be hospitalized or institutionalized by their husbands, parents, or other family members, which contributes to the wider conversation regarding a woman's power to make all decisions regarding her own body, including both limiting and enabling procedures, or whether she wishes to receive treatments at all, and under what structural parameters is that autonomy to be limited. Lack of reproductive power also includes decisions made regarding tubal ligations and sterilization, on behalf of a girl or a woman by their families, such as in the case of the "Pillow Angel" or Rosemary Kennedy [37,38]. 
Pressuring women to adhere to cookie cutter expectations can also make navigating through life a hardship. Not all women can afford to be mothers. The aftermath of neoliberalism and the systematic breakdown of regulation caused a staunchly disproportionate impact on minority women in the United States, and there are partisan conflicts in appropriations, which removes important social programs in favor of national economic growth. Women utilize social programs more often than men, and single, black and Hispanic mothers of multiple children are a particularly large, vulnerable group in need of these resources, which are typically the first line-items to go in a national budget [13]. Unfortunately, the voices of the women who need these programs are not at the table when decisions are made, and the decision-makers are typically white, wealthy men. There have been some recent historical triumphs in Congressional representation of colored women, but United States has a long way to go before this demographical representation in politics will be able to propel the momentum for social change on behalf of their constituents.

The disavowing of marginalized women by not giving them reproductive choice, or resources when there is lack of choice, affirms a "racialized, gendered, and sexualized life," and that life and death is treated as "binary", and lack of protection and support leads to an "exacerbation of minoritized death" [53]. The opinion that minority women should simply stop having children is problematic for this reason, when they may not have sexual agency either. Their ability to negotiate the use of condoms, particularly in machismo cultures, is also related to their lack to birth control, which will likely result in a pregnancy at some point in time. Many of these women may also have religious or cultural limitations to contraceptives, so judging or stereotyping their pregnancies or number of children, entirely lacks a realistic grasp of the social issues.

Women may also have other reasons for either wishing to terminate a pregnancy, or alternatively, bearing as many children as she can, and the latter of which is a common practice in some countries. There are many anthropological theories to support this in Brazil, for example, including the complexity of moral justification, a concept by which some women may make an immoral or unethical decision, or act in a socially or legally consequential manner, yet defend the action in a way that makes it seem justified. Examples include the way in which some poor, Brazilian women may to allow their weakest child to die, appearing to do so without mourning, but all is not what it seems [56].

Field studies look at the decisions that the poorest women in Brazil make on a daily basis, in order to ensure survival, which may mean feeding and caring for their strongest children, while the weakest go without, knowing that they will probably die [56]. This is because these women must make the choice to spend their limited resources on the viable children. Like many women in developing countries, reproductive power is also instilled via strict religious practices, such as Catholicism in Brazil, where contraceptives and abortions are not only dissuaded, but are also in some places illegal and definitely inaccessible.
Brazil has had a long history of disallowing tubal ligations for women, as it would limit their ability to bear children, and that choice is considered to be not hers, but that of their husband's and God. To this end, tubal ligation is against their religious code, and therefore it carries stigma, and it may be difficult to find a skilled, safe, and licensed doctor to perform the procedure, if it also against their religion.

Women in many of these countries are also encouraged to have as many children as possible, because of the high rate of child mortality. Some women bury more children than survive. This issue may bear some relevance to the discussion regarding why some women choose not to terminate a pregnancy, regardless of genetic testing outcome. Literature suggests several various reasons for this, such as perhaps it is due to

- a lack of understanding of the scope of the disability or illness focused in the testing,

- $\quad$ using the test instead to prepare for a disabled child (rather than as an indicator to terminate),

- the concern that they may not be able to have another, future pregnancy, or

- $\quad$ possibly feeling equipped to handle a disabled child, because they may already have another/others with disabilities. These reasons would have no bearing on agency or stigma at all, so the aim is to consider all possibilities why women may choose to keep or terminate a pregnancy [29].

\section{Conclusion}

The intention here is to highlight that the topic of abortion and the contentious opposition of pro-life and pro-choice views must avoid being the sole focus and target of concern regarding women's reproductive power. When the hot button issue arose regarding whether Planned Parenthood should be defunded in the United States, conservative women demanded a call to end the governmental support of an abortion agency. This was a remarkably incorrect and exaggerated assertion, as Planned Parenthood provides a wide range of services, with only a small percentage attributable to abortions [57]. Not only that, but Planned Parenthood connects women with safe providers, but that is not all that they do, as the agency is also known for their qualified care of men, women, children, LGBTQ, and minority women, who seek a wide range of services, from general health to gynecological care, as well as access to birth control and prophylactics. The bigger picture is that without Planned Parenthood and similar organizations, the rate of unwanted pregnancies, and the subsequent need for abortions, would be higher without affordable access to birth controls, which is one of the larger services they provide.

It is obvious that women on both sides of the choice argument have strong convictions, often based in personal, cultural, and religious beliefs. Discourse on the premises and practices of early termination of pregnancy can be critical of its intent, without negating a woman's right to her own principles, because they are uniquely her own, and the decision is about her own body. Another compounding issue is the narrowed view and substantial superiority complex in terms of religious belief, with religious conservatives asserting that their views 
should be the standard by which abortion morality must be set. However, in argument of religious freedom, which is the case in the United States, this moral compass is also individualized.

Supporting women who steadfastly hold onto any value, even if they starkly contrast one another, accentuates that the concept of herstory, and the value of lived experiences, are an invaluable part of advocacy $[13,58]$. A collective of women in social movement is compelling in effecting change. In the United States, this has been demonstrated through first and second wave feminism, such as the women's suffrage movement's constitutional achievement for women's voting rights, and by landmark court cases, such as with Roe v. Wade in the Supreme Court. However, when women en masse are ignored or when their votes may be outnumbered, particularly in instances where a bill or amendment of feminist, disability, or marginalized significance is at stake, it may then be the voice of individual experience that will protect the value of women's bodies.

The sharing of these experiences is an act of "becoming visible," using transparency as power. When any marginalized body has been excluded by society or state, lived experience is a witness to the value of inclusion. It is "a reliable source of information," because it is the difference between theory and praxis, or "perception and reality," and it legitimizes a body that is in danger of being disavowed [58].

These experiences may reason why a woman may choose to participate in fetal genetic testing, or why she may not. They may defend her reason for terminating a pregnancy, based on the results of testing, or alternatively, regardless of the consequence, decide to give birth to a potentially defective child. These experiences may protect her reasons for having an abortion, regardless of if others think it is an acceptable or moral rationalization. These experiences may be her truth that societal discrimination and social determinants of health prevent her from the justification of bringing a disabled child into the world she knows. By contrast, her experiences may strengthen her conviction that disability is not limiting, and that she has the resources to support a disable child's potential in his or her life. Her experiences may validate the oppression, violence, and victimization she has faced, solely based on her gender, and the lack of opportunity and agency she has faced, which weighs into prenatal gender preference [59].

Practice and belief may sometimes be contradictory and situational. Paradox may exist between health behaviours and societal norms. We can be critical of practice without victimizing those who believe they are making an informed choice. Final$1 y$, the work of feminist disability theory should continue to question the premise of fetal testing, and whether it is truly for the empowerment of women to have unabridged agency over her reproductive choice, or if it is to quell or suppress a biologically-different community of people from the greater society.

\section{References}

1. Kelly M (2019) What Abortion Was Like In The U.S. Before Roe V. Wade. Npr.org.

2. Respect for Unborn Human Life: The Church's Constant Teaching | USCCB. Usccb.org (2020).

3. Abortion Laws State by State - Whole Woman's Health. Whole Woman's Health (2020).

4. Fetal Development \& Abortion | First Coast Women's Services. First Coast Women's Services (2020).

5. States with Gestational Limits for Abortion. KFF (2020).

6. Where is Abortion Illegal? | Abortion Limits by State. Plannedparenthoodaction.org(2020).

7. Willse C (2015) The Value of Homelessness: Managing Surplus Life in the United States (University of Minnesota Press, Minneapolis, MN, 2015).

8. Here's the latest point in pregnancy you can get an abortion in all 50 states. Business Insider(2020).

9. How far along can you be to get an abortion?. Plannedparenthood.org(2020).

10. Why an abortion law ruling triggered mass protests in Poland. AP NEWS (2020).

11. Poland Delays a Near-Total Ban on Abortion. Nytimes.com (2020).

12. After Massive Public Outcry, Polish Parliament Rejects Total Abortion Ban | Center for Reproductive Rights. Reproductiverights.org (2020).

13. Mohanty C (2003) Feminism Without Borders: Decolonizing Theory, Practicing Solidarity (Duke University Press, Durham, NC, 2003).

14. The World's Abortion Laws | Center for Reproductive Rights. Reproductiverights.org (2020).

15. Men C, Friesan K, Socheat C, Nirmita H, Mony C (2011) Gender as a social determinant of health: Gender analysis of the health sector in Cambodia. Who.int.

16. Farmer P (1999) Infections and Inequalities: The Modern Plagues (The Regents of The California Press, Berkeley, 1999).

17. Pomeroy C, American Medical Association Journal of Ethics, in press.

18. Harmon B, Schmidt M, Escobar F, San Diego E, Steele (2020) Filling the Gaps: The Role of Faith-Based Organizations in Addressing the Health Needs of Today's Latino Communities. Journal of Religion and Health (2020).

19. Jesudason S, Epstein J, Contraception, in press.

20. If you're pro-life, you might already be pro-choice. The Conversation (2020).

21. Tohar V, Asaf M, Kainan A, Shahar R (2007) An Alternative Approach for Personal Narrative Interpretation: The Semiotics of Roland Barthes. International Journal of Qualitative Methods 6: 57-70.

22. Dilation and curettage (D\&C) - Mayo Clinic. Mayoclinic. org (2020).

23. Mohanty C (1988) Under Western Eyes: Feminist Scholarship and Colonial Discourses. Feminist Review 61.

24. Hattery A, Smith E (2018) Policing Black Bodies: How Black Lives are Surveilled and How to Work for Change (Rowman \& Littlefield, Lanham, Maryland, ed. 1, 2018).

25. Timsit A (2020) One city has created a blueprint for tack- 
ling the opioid epidemic. Quartz.

26. Melillo G (2020) Racial Disparities Persist in Maternal Morbidity, Mortality and Infant Health. AJMC.

27. Racial and Ethnic Disparities Continue in Pregnancy-Related Deaths | CDC Online Newsroom | CDC. Cdc.gov (2020).

28. Deer S (2015) The Beginning and End of Rape: Confronting Sexual Violence in Native America (University of Minnesota Press, Minneapolis, MN, ed. 1, 2015).

29. Hubbard R (1997) The politics of women's biology (Rutgers Univ. Press, New Brunswick, NJ, 1997).

30. Lamp S, Cleigh W, Hall K (2011) (Ed.), Feminist Disability Studies (Indiana University Press, Bloomington, Indiana, 2011).

31. Garland-Thomson R (2002) Integrating Disability, Transforming Feminist Theory. NWSA Journal, Feminist Disability Studies 14: 1-32.

32. Snyder S, Mitchell D, Journal of Literary \& Cultural Disability Studies, in press.

33. Saxton M (2018) Disability Rights and Selective Abortion, The Disability Studies Reader (Routledge, New York, New York, ed. 5, 2018).

34. Kafer A (2003) Compulsory Bodies: Reflections on Heterosexuality and Able-bodiedness. Journal of Women's History 15.

35. Foucault M (1978) The History of Sexuality: Volume 1: An Introduction (Vintage Books, New York, New York, 1978).

36. Patterson A, Satz M, Hypatia, in press.

37. Hall K (2011) Feminist Disabilities Studies (Indiana University Press, Bloomington, Indiana.

38. Biehl J (2005) Vita: Life in a Zone of Social Abandonment (University of California Press, Los Angeles, CA, 2005).

39. Parens E, Asch A, The Hastings Center Report, Special Supplement, in press.

40. Blackshaw B, Ethical Theory and Moral Practice, in press.

41. Mintz S, Hall K (2011) (Ed.), Feminist Disability Studies (Indiana University Press, Bloomington, Indiana, 2011).

42. Delgado R, Droz Keyes J (1974) Parental Preferences and Selective Abortion: A Commentary on Roe v. Wade, Doe v. Bolton, and the Shape of Things to Come. Washington University Law Quarterly 1974.

43. Butler J (2004) Undoing Gender (Routledge, New York, NY, 2004).

44. Smith A (2011) Hideous Progeny: Disability, Eugenics, and Classic Horror Cinema (Columbia University Press, New York, 2011).

45. Gomez J, Kennedy Institute of Ethics Journal, in press.

46. McKinney C (2016) Selective Abortion as Moral Failure? Revaluation of the Feminist Case for Reproductive Rights in a Disability Context. Disability Studies Quarterly. 36 (2016).

47. McRuer R (2016) Crip Theory: Culture, Signs of Queerness and Disability (New York University Press, New York, NY, 2006).

48. Farmer P (2005) Pathologies of Power: Heath, Human Rights, and the New War on the Poor (University of Cali- fornia Press, Berkeley and Los Angeles, 2005).

49. Hubbard R, Wald E (1999) Exploding the Gene Myth: How Genetic Information is Produced and Manipulated by Scientists, Physicians, Employers, Insurance Companies, Educators, and Law Enforcers (Beacon Press, Boston, Massachusetts, 1999).

50. Gould J, Bioethical Inquiry, in press.

51. Ethics of Designer Babies | The Embryo Project Encyclopedia. Embryo.asu.edu (2020).

52. Kittay E, Kennedy Institute of Ethics Journal, in press.

53. Hong G (2015) Death Beyond Disavowal: The Impossible Politics of Difference (University of Minnesota Press, Minneapolis, MN, 2015).

54. Szakacs G (2020) Orban offers financial incentives to boost Hungary's birth rate. U.S. (2020)

55. Hungary tries for baby boom with tax breaks and loan forgiveness. BBC News (2020).

56. Scheper-Hughes N (1992) Death without Weeping: The Violence of Everyday Life in Brazil (University of California Press, Berkeley, 1992).

57. Gore A (2020) Planned Parenthood's Services - FactCheck.org. FactCheck.org (2020)

58. Scott J, Critical Inquiry, in press.

59. Miller-Gallant A (2008) Sculpting Body Ideals: Alison Lapper Pregnant and the Public Display of Disability. Disability Studies Quarterly.
Copyright: (C)2020 Shannyn R. Snyder. This is an open-access article distributed under the terms of the Creative Commons Attribution License, which permits unrestricted use, distribution, and reproduction in anymedium, provided the original author and source are credited. 